\title{
Why is it important to use improvement methods to address chronic care priorities in primary care?
}

\author{
M. Rashad Massoud* and Leighann E. Kimble \\ Quality \& Performance Institute, USAID Applying Science to Strengthen and Improve Systems (ASSIST) Project, University Research Co., LLC, USA
}

\section{Introduction}

Primary healthcare covers a broad range of healthcare services and involves the basic, first-contact care for patients. As the first level of care, primary healthcare also bears the burden of delivering longterm care to patients [1-2]. For this reason, access to quality primary healthcare for all individuals is essential. With long-term chronic care conditions representing over $80 \%$ of the global burden of illness, the capacity and quality of primary healthcare to address this burden is even more clear [3-7].

In primary care, especially with chronic conditions, factors outside of healthcare, including social and family considerations must be addressed. This requires a multidisciplinary team to address the complex health needs of primary care patients. This also requires the engagement of patients and their families in managing their chronic conditions. Given the broad range of providers required to deliver primary care, maintaining quality of care between different services becomes complex, particularly when the services are not integrated. Many of the defects in delivering healthcare occur in handovers between professional functions at different steps in the processes of the healthcare delivery system.

Quality improvement methods reorganize processes of healthcare delivery using multidisciplinary teams, care integration, and engagement of providers, patients, and families. Quality improvement also recognizes healthcare as complex adaptive systems and provides the means for healthcare processes to be organized in a way that responds and adapts to context [8-11]. This paper emphasizes the need to better utilize and integrate quality improvement approaches to address the growing needs in primary healthcare delivery.

\section{The burden of chronic care conditions}

$80 \%$ of the global burden of illnesses is due to chronic care conditions. Included in this burden is the need to address long-term care for patients suffering from infectious diseases such as HIV/AIDS. As reflected in the Chronic Care Model in Figure 1 below, addressing the chronic care burden requires the health system to be organized in a way that integrates health processes at multiple levels and allows patients to be informed and activated in their care [12-13]. To have a health system operate in this way requires healthcare processes to be reorganized in a way that supports integrated multidisciplinary teams and the engagement of patients in their care [14-19].

Quality improvement provide the means of reorganizing care delivery to achieve these goals. By testing and implementing changes in healthcare processes, guided by real-time data, quality improvement gives providers the tools to improve the way in which inputs into the system are used, with the goal of improving health system outcomes. Along the way to testing and implementing health system processes, quality improvement methods focus on teamwork. Engaging those involved in healthcare delivery processes creates a vibrant multidisciplinary team capable of suggesting, testing, and implementing changes needed in care processes, with a common goal of yielding improved outcomes.

\section{An essential role for patients and multidisciplinary teams in primary care chronic care management}

Factors outside of the healthcare system, such as food security, poverty, homelessness, and other social considerations play a role in primary healthcare, particularly when caring for patients with chronic conditions. To adequately address the complex needs of primary care patients, multidisciplinary teams must involve traditional healthcare professionals, in addition to other clinical and social services professionals on the care team that can work together to design, improve, and manage care delivery processes in the best interest of

\section{The Chronic Care Model}

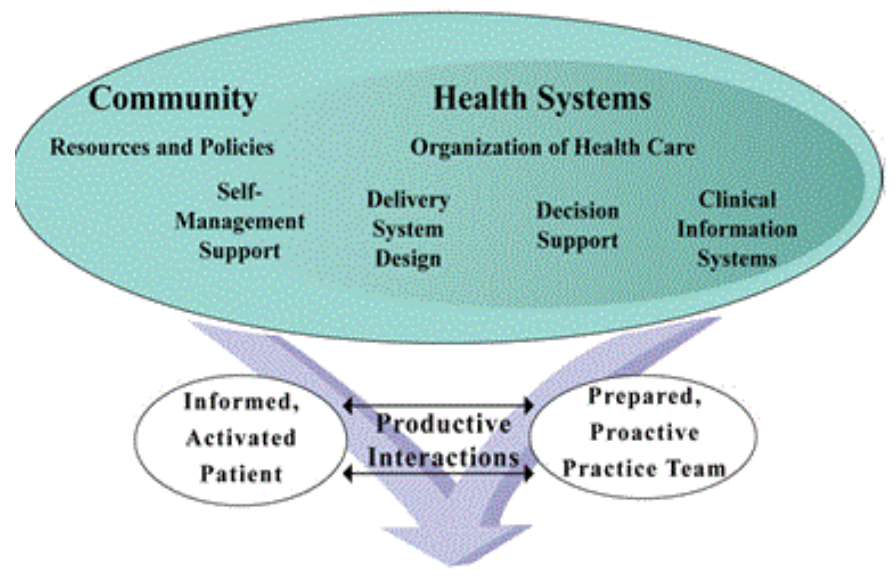

Improved Outcomes

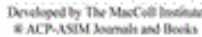

Figure 1. The Chronic Care Model.

Correspondence to: M. Rashad Massoud, Quality \& Performance Institute, USAID Applying Science to Strengthen and Improve Systems (ASSIST) Project, University Research Co., LLC, USA, Tel: +1 (301) 941-8448; Fax: +1 (301) 9418427; E-mail: rmassoud@urc-chs.com

Received: June 20, 2017; Accepted: July 17, 2017; Published: July 19, 2017 
patients. Improvement Methodology focuses on the importance of teamwork in reaching improved care outcomes.

Chronic care conditions require long-term treatment options and the patients to manage their own care outside of the healthcare system. Due to their involvement in management of their longterm care, patients and their families play a huge role in the quality improvement team. By recognizing the important role of patients, quality improvement methods create opportunities for increased patient engagement and empowerment in healthcare processes. Including patients on improvement design teams allows healthcare providers to design care delivery from the patient and family perspective. Involvement of patients and their families also breaks the power differential between patients and providers, allowing patients to more directly provide feedback regarding their care to their providers.

\section{Understanding and improving processes in healthcare delivery}

Improvement methodology involves the iterative nature of testing changes to see if they yield improvements, and readjusting based on the results achieved. Iteration and adaptation is necessary in the complex setting of healthcare delivery. Flexibility allows for evidence-based medicine to be reliably delivered to patients - constant analysis and reevaluation allows for changes to be made when healthcare delivery processes are not effectively delivering evidence-based medicine to patients in need, when they need it.

By testing and evaluating changes, healthcare delivery processes can be streamlined to ensure that only value-added steps are taking place and that steps that are not value added are removed from the care delivery process. In this way, improvement methodology not only yields better results, but reduces waste resulting from unnecessary steps in the care delivery processes.

\section{References}

1. WHO (2004) Primary Healthcare: Main Terminology, Primary health care. World health organization.

2. WHO (2004) What are the advantages and disadvantages of restructuring a health care system to be more focused on primary care services? World health organization, Europe.
3. Bengoa R, Kawar R, Key P, Leatherman S, Massoud R, et al. (2006) Quality of Care: A Process for Making Strategic Choices in Health Systems. World Health Organization, Geneva, Switzerland.

4. Health Disparities Collaborative (2002) Diabetes Training Manual. Institute for Healthcare Improvement.

5. Epping-Jordan J, Yach D, Bengoa R, Kawar R, Sabate E (2001) Innovative Care for Chronic Conditions. World Health Organization.

6. Sugarman JR, Smith-Jones K, Franzen M, Bearden T (2017) Primary Care in the United States: Lessons Learned to Inform Global Efforts to Improve Primary Care. Qualis Health, Seattle, WA.

7. Wagner EH, Austin BT, Davis C, Hindmarsh M, Schaefer J, et al. (2001) Improving Chronic Illness Care: Translating Evidence into Action. Health Aff (Millwood) 6: 64-78.

8. Kabcenell A, Langley J, Hupke C (2006) Innovations in planned care. Institute for Healthcare Improvement.

9. Massoud MR, Ottosson A, Nsubuga-Nyombi T, Karamagi E, Stern A, et al. (2016) Improving Health Care. Training Participant Guide. USAID ASSIST Project, University Research Co., LLC (URC), Bethesda

10. Massoud R, Askov K, Reinke J, Miller Franco J, Bornstein T, et al. (2001) A Modern Paradigm for Improving Healthcare Quality. Quality Assurance Project, University Research Co., LLC (URC), Bethesda.

11. Langley GJ, Moen RD, Nolan KM, Nolan TW, Norman CL, et al. (2009) The Improvement Guide: A Practical Approach to Enhancing Organizational Performance, (2nd Edn) San Francisco, Jossey-Bass.

12. Wagner EH (1998) Chronic disease management: what will it take to improve care for chronic illness? Eff Clin Pract 1: 2-4.

13. Bodenheimer T, Wagner EH, Grumbach K (2002) Improving primary care for patients with chronic illness: the chronic care model, Part 2. JAMA 288: 1909-1914. [Crossref]

14. Blumenthal D, Kilo CM (1998) A report card on continuous quality improvement Milbank $Q 76$ : 625-648, 511. [Crossref]

15. Kilo CM, Wasson JH (2010) Practice redesign and the patient-centered medical home: history, promises, and challenges. Health Affairs 29: 773-778.

16. Scherger J (2010) Creating ideal primary care. Medical Home News 2: 1-5.

17. Craig C, Eby D, Whittington J (2011) Care coordination model: better care at lower cost for people with multiple health and social needs. Institute for Healthcare Improvement.

18. Glasby J, Alakeson V, Duffy S (2013) Doctor knows best? The use of evidence in implementing self-directed support in health care. Health Services Management.

19. Berwick DM (2013) Promising care: How we can rescue health care by improving it. Wiley.

Copyright: (C2017 Massoud RM. This is an open-access article distributed under the terms of the Creative Commons Attribution License, which permits unrestricted use, distribution, and reproduction in any medium, provided the original author and source are credited. 